\title{
Acceptability of Amaranth Grain-based Nutritious Complementary Foods with Dagaa Fish (Rastrineobola argentea) and Edible Termites (Macrotermes subhylanus) Compared to Corn Soy Blend Plus among Young Children/Mothers Dyads in Western Kenya
}

\author{
Silvenus O. Konyole ${ }^{1}$, John N. Kinyuru ${ }^{2}$, Bethwell O. Owuor ${ }^{3}$, Glaston M. Kenji ${ }^{2}$, Christine A. Onyango ${ }^{2}$, \\ Benson B. Estambale ${ }^{1}$, Henrik Friis ${ }^{4}$, Nanna Roos ${ }^{4} \&$ Victor O. Owino ${ }^{5}$ \\ ${ }^{1}$ Institute of Tropical \& Infectious Diseases, University of Nairobi, Nairobi, Kenya \\ ${ }^{2}$ Department of Food Science \& Technology, Jomo Kenyatta University of Agriculture \& Technology, Nairobi, \\ Kenya \\ ${ }^{3}$ Department of Biology, Catholic University of Eastern Africa, Nairobi, Kenya \\ ${ }^{4}$ Faculty of Science, University of Copenhagen, Copenhagen, Denmark \\ ${ }^{5}$ International Nutrition Programme, University of California-Davis, Davis California, USA \\ Correspondence: Silvenus O. Konyole, Institute of Tropical \& Infectious Diseases, University of Nairobi, P. O. \\ Box 19676-00200, Nairobi, Kenya. E-mail: konyole2000@yahoo.com
}

Received: May 8, 2012 Accepted: May 23, 2012 Online Published: July 2, 2012

doi:10.5539/jfr.v1n3p111 URL: http://dx.doi.org/10.5539/jfr.v1n3p111

\begin{abstract}
We assessed acceptability of two flours and porridges of complementary foods based on germinated grain amaranth and maize with or without edible termites and dagaa small fish named "Winfood Classic" (WFC) and "Winfood Lite" (WFL), respectively, compared to Corn Soy Blend Plus (CSB+) among mothers and young children. A total of 57 children consumed each of the three foods on separate days with one-day washout between foods. Each food was considered acceptable if the child consumed at least 75\% of the serving. Most mothers preferred WFL flour and porridge (63.2\% and 70.2\%, respectively) compared to WFC (24.4\% and $10.5 \%)$ and $\mathrm{CSB}+(12.3 \%$ and $19.3 \%)$. Children consuming at least $75 \%$ of served porridge were $43 \%, 19.6 \%$ and $21 \%$ for WFL, WFC and CSB+, respectively. No adverse effects were observed for all the foods throughout the study period and follow up lasting 4 weeks. All foods were acceptable and can be further developed and be tested for efficacy.
\end{abstract}

Keywords: complementary food, amaranth grain, Dagaa fish, termites, acceptability, CSB+

\section{Key messages}

(1). Complementary foods developed from locally available food materials are possible and when well formulated is appropriate for resource poor settings.

(2). Affordable complementary foods formulations are needed, but such new formulations must be acceptable and not associated with any adverse health effects among target children

\section{Introduction}

Accessibility to affordable, healthy food is essential for good health as poor nutrition is one of the major determinants of impaired growth and development, acquisition of certain diseases and later chronic diseases (Allen, 2003). Children are most vulnerable to poor nutritional status during the complementary feeding periods when both macro and micronutrients are insufficient to maintain growth and development, leading to malnutrition (Dewey \& Brown, 2003). One way of sustainably reducing malnutrition is by using available traditional and indigenous plant and animal foods to prepare complementary foods that are both hygienically and nutritionally adequate to meet the needs of fast-growing infants and young children (WHO, 2008).

In some communities in Kenya, entomophagy (the practice of eating insects) has been common and widespread depending on the availability of the insects and the ability to trap them for use (Ayieko, 2007). Although small 
fish such as dagaa (Rastrineobola argentea) have been used in the preparation of complementary foods in some settings, there is scarcity of data on acceptability and tolerance of such foods among infants and young children, as well as their caretakers. The objective of this study was to determine acceptability of nutritionally dense complementary foods developed from traditional ingredients in comparison to Corn Soy Blend plus (CSB+), a standard humanitarian food ration, among local mothers and young children. This study was a prelude to an intervention study aimed at the evaluation of the effects of the amaranth grain-based complementary foods processed using dagaa fish and edible termites on growth and micronutrient status of infants in western Kenya.

\section{Material and Methods}

\subsection{Foods Description}

The two complementary foods named as "Winfoods" were processed using germinated grain amaranth, maize soy oil and sugar but differed in the content of dagaa and edible termites. Winfood Classic (WFC) had 3\% dagaa and $10 \%$ edible termites added, while Winfood Lite (WFL) had neither dagaa nor termites added. The ingredients were chosen after focus group discussions and interviews with mothers and health workers showed (results not shown) that some of the ingredients were available within the study area and were commonly used for the preparation of complementary foods (Kinyuru et al., 2010). "Winfoods" acceptability was compared to that of Corn-Soy Blend (CSB+) processed to World Food Programme specifications of 2010 (World Food Program, 2010) and purchased from Wanjis Foods Industries Ltd, Nairobi, Kenya. All the ingredients were locally identified and sourced from within the study region. WFC and WFL were pre-cooked based on heat extrusion. The final microbial analysis was carried out and safety ascertained by the Kenya Bureau of Standards and found to comply with limits set for CSB + meant for similar target groups (World Food Program, 2010). $\mathrm{CSB}+$ was also extruded and availed in flour form.

Estimated nutrient values of the developed complementary foods and the CSB+ are as shown in Table 1. The values are as obtained from analytical values. They acted as a guide during the nutrient optimization process in order to achieve nutrient dense blends. On cost analysis, WFL had the lowest cost (USD 1.82/ kg) due to the fact that it did not have the termites while WFC cost (USD 3.76/kg). The cost of the foods was lower than an average commercially processed complementary food which retailed at about USD 7.0/ $\mathrm{kg}$ in Kenya (as per market survey of November, 2011). One way to reduce the cost is by encouraging more termite harvesters to harvest thereby increasing supply and consequently lowering the price. Currently, the termite is a delicacy in Western Kenya where it retails at USD 12.0 in the markets when they are in season. The prices go even higher to USD 18.0 when they are off season. However, the developed complementary foods may be affordable by the target population in western Kenya where the ingredients are sourced from and thus the middlemen effect which increases the prices drastically is eliminated when sourcing the termites (Kinyuru et al., 2010).

Table 1. Estimated nutrient values of complementary foods

\begin{tabular}{lccc}
\hline Nutrient & CSB + & WFC & WFL \\
\hline Energy $(\mathrm{kcal} / 100 \mathrm{~g})$ & 380 & 539.72 & 496.21 \\
Protein $(\mathrm{g} / 100 \mathrm{~g})$ & 14.67 & 21.52 & 16.81 \\
Fats $(\mathrm{g} / 100 \mathrm{~g})$ & 6.24 & 18.49 & 13.44 \\
Calcium $(\mathrm{mg} / 100 \mathrm{~g})$ & 470 & 24.70 & 16.81 \\
Iron $(\mathrm{mg} / 100 \mathrm{~g})$ & 6.5 & 20.25 & 14.09 \\
Zinc $(\mathrm{mg} / 100 \mathrm{~g})$ & 5 & 5.10 & 4.06 \\
\hline
\end{tabular}

\subsection{Study Area}

The study was carried out at Makunga Sub-District Hospital, Mumias District of Kakamega County, Western Kenya in March 2011. The site was chosen to reflect the resource poor settings targeted in the subsequent efficacy study and in the region where the foods used to process the products are already accepted. Most of the inhabitants of the area have turned their farms into small plantations of sugar cane with the average size of plot holdings of 4 acres in an effort to earn cash from the cash crop. The sugar cane is harvested after 18-24 months. In the meantime, farmers are left without a viable source of income till the next harvesting season which has left many families with very small pieces of land that are used for food crops resulting into increased malnutrition in the area especially among children. 


\subsection{Study Design and Data Collection Methods}

The study was done in three phases where phase 1 involved hedonic ranking by mothers of three flours and, subsequently, porridges as detailed by Meilgaard et al. (2007). The porridges had been prepared by the study team prior to the ranking. Mothers evaluated colour, taste, texture and smell of flours and prepared porridges based on a 5-point hedonic scale (from "5"-like very much, to "1"-dislike very much) (Meilgaard et al., 2007). Overall comments about the products and how to improve them for feeding infants and young children were also captured.

Phase 2 involved having the mothers centrally prepare the porridges and feed the infants. In a cross-over design children were initially randomised to receive one of the three study foods (WFL [ $\mathrm{n}=15]$, WFC [n=17], CSB+ $[\mathrm{n}=15])$ on the first day followed by a one-day washout after which they switched to the second porridge on the 3rd day followed by another one-day washout period before completing with the third porridge on the 5th day. On each feeding day the study team observed how the child reacted during feeding and scored response based on a 5-point hedonic scale (Meilgaard et al., 2007). About $150 \mathrm{ml}$ of porridge was offered to the infant in a graduated feeding cup. The amount of porridge consumed was calculated by subtracting amount left and spilt from $150 \mathrm{ml}$. The mother/infant pairs were divided into three groups and each infant was scheduled to eat one product one day over a 5 -day period with a wash-out day in separating the porridges.

Phase 3 involved the mothers taking home $100 \mathrm{~g}$ of a flour on each of the three visits at the health facility, preparing the food at home in their usual way and feeding the enrolled child as well as any other willing person at home. On subsequent visits mothers were asked how well the child and any other person in the household liked the porridge they prepared at home and responses recorded on a 5-point scale.

Morbidity data for children including diarrhoea, stomach-ache, vomiting, skin rashes and difficulty in breathing, were collected by a two-day recall at recruitment and at every subsequent visit along with anthropometric measurements once for weight, length and mid upper arm circumference. For infants, each food was deemed acceptable if the child consumed at least $75 \%$ of the serving and if less than $10 \%$ of adverse effects cases were reported for that particular test food based on similar work (Valid International, 2006). Mothers attending the Makunga Sub-District Health Centre with infants 6-24 months of age were assessed for eligibility to participate in the acceptability study. To be eligible, the infant had to be 6-24 months old, the caregiver had to be willing to prepare and take/serve the porridge as advised. Moreover, the infant had be free of any evidence of chronic disease and weighed at least $2500 \mathrm{~g}$ at birth. Those with chronic illness requiring medication, genetic disorders interfering with normal growth were excluded and referred for treatment at the partnering Makunga health facility. The mothers were not forced to take part in the study and the purpose of the study was explained to obtain informed consent and further permission obtained from the Mumias District Health Management Team, The Chief and other local administrators. All caretakers/mothers gave written informed consent.

\subsection{Data Analysis}

All data collection forms were checked by the supervisors in the field to allow immediate re-visits for gross errors or missing data. Data was analysed using analysed by SPSS (Version 17) (SPSS, 2010) and anthropometric data was analysed using WHO Anthro (WHO Anthro 3.2.2). Means and standard deviations were calculated for acceptability of the sensory attributes of the complementary foods. A two-way analysis of variance (ANOVA) was conducted to test for significant differences $(p<0.05)$ in the sensory attributes (appearance, smell, taste, and texture) among the three foods. Mothers' comments were also recorded verbatim and organised into themes.

\section{Results}

\subsection{Demographic and Anthropometric Information}

Fifty seven child/mother pairs were recruited into the study with 31 of the infants/children being boys and 26 girls. Descriptive statistics for the anthropometric information before the acceptability study are presented in Table 2. Age of the participating infants ranged from 6 months to 24 months. Boys had a mean age of 12.3 months while the girls had a mean age of 11.3 months. Girls had a slightly lower LAZ than the boys $(-0.2$ and 0.3 , $\mathrm{p}=0.001)$, respectively, though none of them were stunted $(\mathrm{LAZ}<-2)$.

None of the participating infants were wasted (WLZ $<-2$ ) and the average WLZ was not significantly different $(p \leq 0.05)$ between boys and girls. All the infants participating in the study were well nourished (MUAC $>12.5)$ 
and were already consuming complementary foods back home while among them, $80.7 \%$ were still breastfeeding.

Table 2. Background demographic and anthropometric information

\begin{tabular}{lll}
\hline & Boys $(\mathrm{n}=31)$ & $\operatorname{Girls}(\mathrm{n}=26)$ \\
\hline Age $($ months $)$ & $12.3 \pm 5.6$ & $11.3 \pm 6.9$ \\
Length $(\mathrm{cm})$ & $75.1 \pm 7.6$ & $74.6 \pm 5.8$ \\
Weight $(\mathrm{kg})$ & $9.5 \pm 2.2$ & $8.9 \pm 1.2$ \\
MUAC $(\mathrm{cm})$ & $14.7 \pm 1.4$ & $14.3 \pm 1.1$ \\
WAZ & $-0.1 \pm 1.2$ & $-0.5 \pm 1.3$ \\
LAZ & $0.3 \pm 1.5$ & $-0.2 \pm 1.3$ \\
WLZ & $-0.2 \pm 1.1$ & $-0.5 \pm 1.6$ \\
Consuming complementary foods $(\%)$ & 100.0 & 100.0 \\
Still breastfeeding $(\%)$ & 80.7 & 80.7 \\
\hline
\end{tabular}

MUAC-Mid Upper Arm Circumference; LAZ-Height/Length for Age Z-score; WAZ-Weight for Age Z-score; WLZ-Weight for Height/Length Z-score.

\subsection{Maternal Food Acceptability}

Data on the sensory evaluation and acceptability of the flours by mothers are presented in Table 3 . The consumers ranked WFL flour highest in terms of colour, smell and texture. The colour and smell of WFL were however not significantly different $(\mathrm{p}>0.05)$ from $\mathrm{CSB}+$ which was being used as a positive control. The colour and smell of WFC flour were significantly lower than in both WFL and CSB+. This could have been due to the addition of dagaa fish and termites added to the composite products that slightly changed the attributes. CSB+'s texture was rated lowest.

Table 3. Sensory evaluation of the products' flours by mothers

\begin{tabular}{llll}
\hline Product & \multicolumn{2}{c}{ Attributes } \\
\cline { 2 - 4 } & Colour & Smell & Texture \\
\hline WFL & $3.9 \pm 0.14^{\mathrm{a}}$ & $3.9 \pm 0.14^{\mathrm{a}}$ & $4.6 \pm 0.07^{\mathrm{a}}$ \\
WFC & $3.3 \pm 0.18^{\mathrm{b}}$ & $3.0 \pm 0.18^{\mathrm{b}}$ & $4.4 \pm 0.12^{\mathrm{a}}$ \\
CSB + & $3.8 \pm 0.16^{\mathrm{a}}$ & $3.8 \pm 0.16^{\mathrm{a}}$ & $2.4 \pm 0.12^{\mathrm{b}}$ \\
\hline
\end{tabular}

Mean $\pm \mathrm{SD} ; \mathrm{N}=57$; Values on the same column with different superscripts are significantly different $(\mathrm{p} \leq 0.05)$.

Similar trends as shown in the flour were reported by the mothers rating of the porridge (Table 4). Mean scores on the five point hedonic scale were $4.0 \pm 0.1$ indicating that the color, smell, taste and texture were liked. There were no significance differences between the mothers' scores for sensory attributes of colour, smell and taste of the WFL and CSB+. WFC's smell and colour were however rated at 2.0 meaning they were slightly disliked even though the texture was slightly liked.

Table 4. Sensory evaluation of the products' porridge by mothers

\begin{tabular}{lllll}
\hline Product & \multicolumn{4}{c}{ Attributes } \\
\cline { 2 - 5 } & Colour & Smell & Taste & Texture \\
\hline WFL & $4.0 \pm 0.1^{\mathrm{a}}$ & $4.0 \pm 0.1^{\mathrm{a}}$ & $4.0 \pm 0.1^{\mathrm{a}}$ & $4.0 \pm 0.1^{\mathrm{a}}$ \\
WFC & $3.0 \pm 0.2^{\mathrm{b}}$ & $2.0 \pm 0.1^{\mathrm{b}}$ & $2.0 \pm 0.2^{\mathrm{b}}$ & $4.0 \pm 0.2^{\mathrm{a}}$
\end{tabular}



CSB+
$4.0 \pm 0.2 \mathrm{a}$
$4.0 \pm 0.1^{\mathrm{a}}$
$4.0 \pm 0.2^{\mathrm{a}}$
$3.0 \pm 0.2^{\mathrm{b}}$

Mean $\pm \mathrm{SD} ; \mathrm{N}=57$; Values on the same column with different superscripts are significantly different $(\mathrm{p} \leq 0.05)$.

WFL was the most preferred flour and porridge $(63.2 \%$ and $70.2 \%$ respectively) by the mothers thus WFL was the most preferred product of the three foods presented. More mothers preferred WFC flour (24.6\%) than CSB+ flour $(12.3 \%)$ while the porridges were preferred at $10.5 \%$ and $19.3 \%$ for WFC and CSB+ respectively by the mothers. All the mothers indicated that they preferred their product of choice due to the inherent properties of color, smell, taste and texture and none indicated that their preferences was based on extrinsic factors.

\subsection{Infant Food Acceptability}

Maternal interpretation of their infant's responses was evaluated at three levels of feeding starting at when the infant sees the food, at the initial food offer and subsequent offers at the health centre. The interpretation indicated that the infants preferred WFL more, in comparison to the other products (Table 5). Infants preferred WFC porridge more than CSB + based on the level of liking at all the three levels of feeding. At subsequent feeding offers, there was no significant difference between WFL and CSB+.

Table 5. Sensory evaluation of the porridge by enrolled infants

\begin{tabular}{llll}
\hline Product & Sees food first & Initial offer & Subsequent offers \\
\hline WFL & $4.2 \pm 0.1^{\mathrm{a}}$ & $4.2 \pm 0.1^{\mathrm{a}}$ & $4.2 \pm 0.1^{\mathrm{a}}$ \\
WFC & $3.6 \pm 0.2^{\mathrm{b}}$ & $3.6 \pm 0.2^{\mathrm{b}}$ & $3.4 \pm 0.2^{\mathrm{b}}$ \\
CSB + & $3.3 \pm 0.2^{\mathrm{c}}$ & $3.3 \pm 0.2^{\mathrm{c}}$ & $3.3 \pm 0.2^{\mathrm{b}}$
\end{tabular}

Mean $\pm \mathrm{SD} ; \mathrm{N}=54$ (3 were lost to follow up); Values on the same column with different superscripts are significantly different $(\mathrm{p} \leq 0.05)$.

\subsection{Amount of Food Consumed}

On average, $73.0 \%$ of WFL porridge was consumed while $48.5 \%$ and $48.0 \%$ of CSB + and WFC were eaten respectively by the enrolled infant during central feeding at the health centre (Table 6). However, the amount consumed significantly increased during home feeding with over $75 \%$ of CSB + and WFL consumed and WFC reporting $68.9 \%$ consumption.

Table 6. Amount of porridge consumed (\%) by infants

\begin{tabular}{lll}
\hline & Central feeding & Home feeding \\
\cline { 2 - 3 } WFL & $73.0 \pm 30.4^{\mathrm{b}}$ & $91.6 \pm 39.5^{\mathrm{a}}$ \\
WFC & $48.0 \pm 34.3^{\mathrm{b}}$ & $68.9 \pm 32.3^{\mathrm{a}}$ \\
$\mathrm{CSB}+$ & $48.5 \pm 33.5^{\mathrm{b}}$ & $75.0 \pm 39.5^{\mathrm{a}}$ \\
\hline
\end{tabular}

Mean \pm SD; Values on the same row with different superscripts are significantly different $(\mathrm{p} \leq 0.05)$.

Upon evaluating different proportions eaten, Figure 1 shows that $43 \%$ of the infants consumed over $75 \%$ of the served WFL porridge. Twenty one (21\%) of the infants consumed over $75 \%$ CSB+ served while $19.6 \%$ of the infants consumed over $75 \%$ of the WFC served. Similar trend was observed for CSB+ and WFC with over $50 \%$ of the respondents consuming less than $50 \%$ of the food served while only $27.8 \%$ of the respondents consumed less than $50 \%$ of the WFL served. 


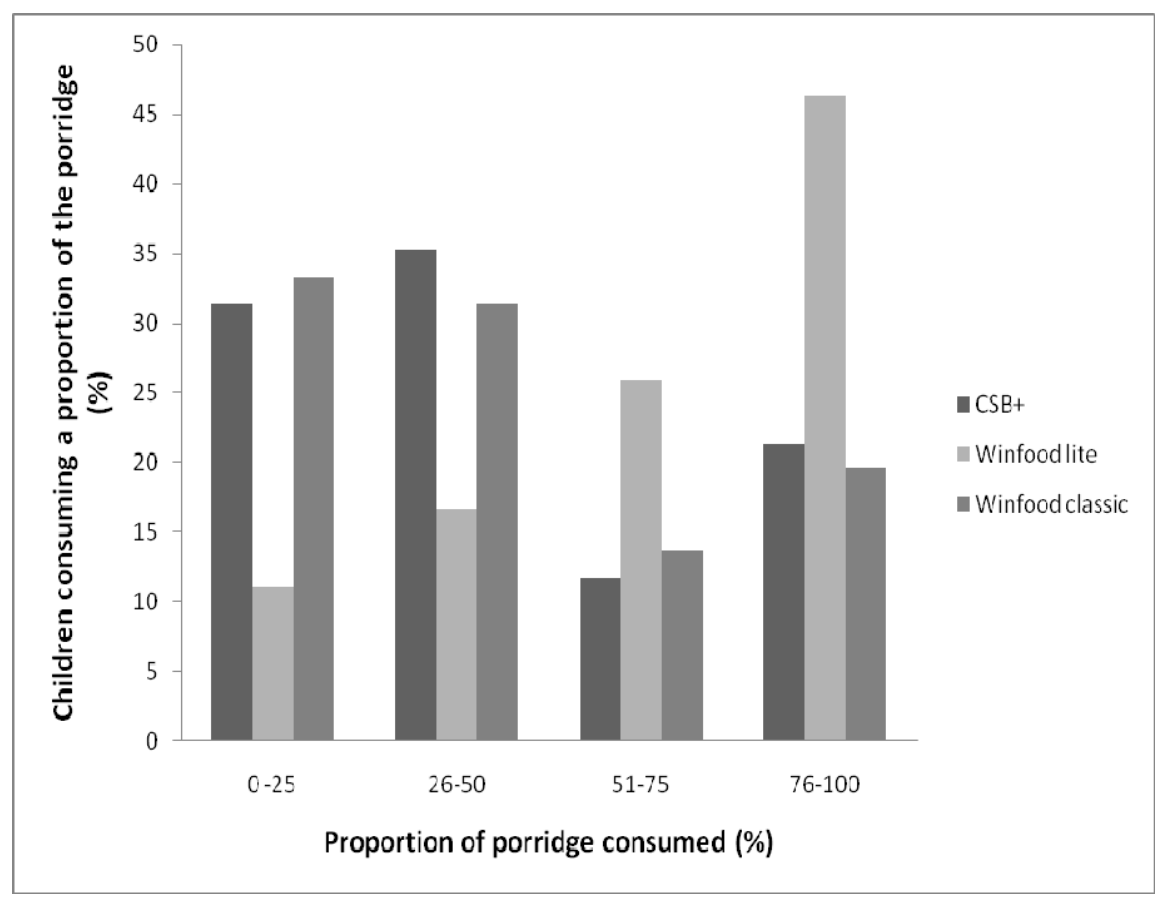

Figure 1. Proportion of porridge consumed by the enrolled young children at the health centre

\subsection{Food Tolerance}

Diagnosis of infant and young child food allergy and intolerance is a challenge due to lack of appropriate communication. In this study, infant tolerance of the foods was evaluated on consuming each of the foods. Adverse health effects on consumption of the foods were evaluated and presented as shown in Figure 2.

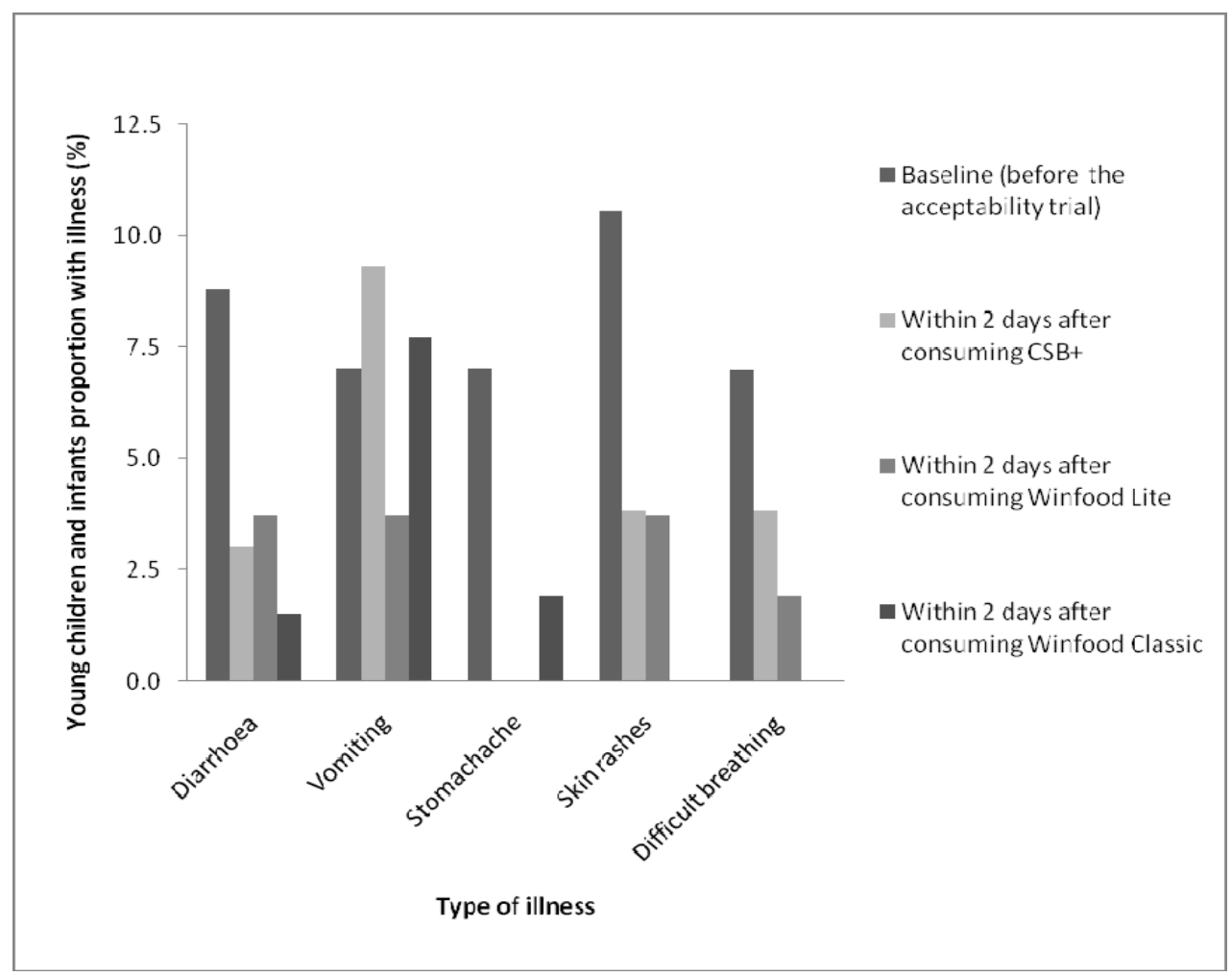

Figure 2. Infant/young child illness just before, during and shortly acceptability study 
In all illnesses evaluated except vomiting, the levels were higher before the acceptability study than after feeding the specific foods. This shows that the level of morbidity was high among the participants with $10.5 \%$ of participants showing signs of skin rashes before the acceptability study. Others illnesses evaluated according to the mothers knowledge were whether the infants had shown signs of fever and cough. Cases of vomiting were reported $(9.3 \%)$ after consumption of $\mathrm{CSB}+$ which was slightly higher than the value before the acceptability study (7\%). Cases of stomach-ache were not reported among the infants who ate WFL and CSB+. However, some symptoms can be difficult to interpret as life-threatening reactions such as the crying, fussing, irritability, inappropriate drowsiness or fright, spitting up, vomiting, loose stool/diarrhoea or abdominal pain/stomach-ache. Within a population, the number of allergic/intolerance cases towards a certain food should not exceed $10 \%$ (Bovell-Benjamin et al., 1999). In this study, all the cases reported were below $10 \%$ threshold required to declare a product to have adverse effects thus even the $9.3 \%$ observed for vomiting was still acceptable.

\subsection{Post-tasting Comments by Mothers}

Mothers were requested to comment on the product. The comments were captured and are represented in the Figure 3. The main comments relating to how to further improve the foods were identified as thickness (consistency) and taste (sweetness). Majority of the mothers (39.4\%) suggested they would prefer WFC with sugar while $23.5 \%$ of the mothers indicated they would prefer a WFC if it had a thicker consistency. Other comments included 'baby likes' and 'good for babies'.

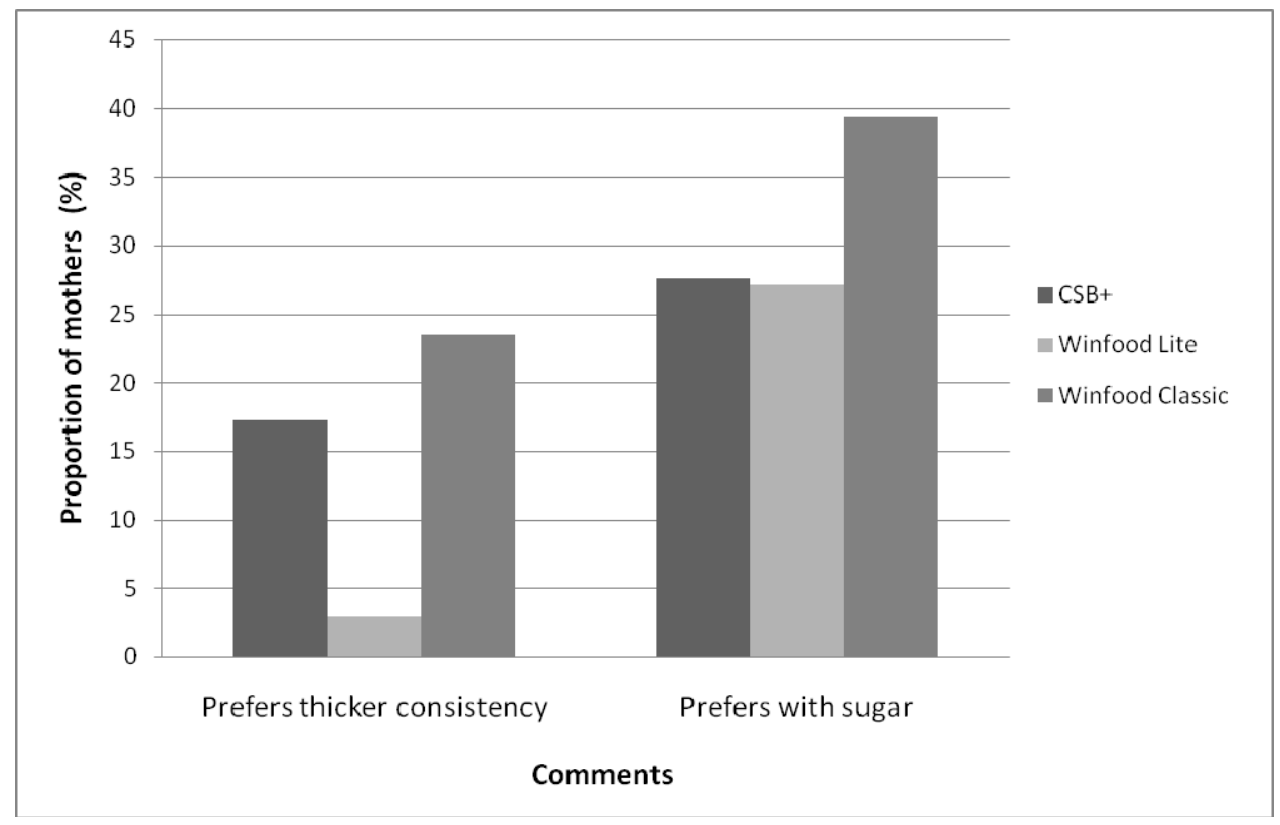

Figure 3. Some post taste comments by mothers

\section{Discussion}

In infants, means for the three porridges were $>3.0$ thus a general liking of all the products with no evidence of allergic reaction from the foods consumed. The observation that both WFL and WFC porridges were generally accepted agrees with previous observations that mothers often find complementary foods processed from locally available staples attractive (Mensa-Wilmot et al., 2001; Owino et al., 2007). It appears that, in addition to a sufficient energy density, sensory qualities of complementary food formulations corresponding to food preferences of mothers and their infants are of importance. It has been noted that dietary quality rather than quantity is a key aspect of complementary food development that needed improvement (Lutter \& Rivera, 2003). Infant age has been found to affect food preferences for consistency of complementary foods (Parker et al., 1998), with infants not showing dislike for some foods that mothers reportedly disliked. However, it is necessary to ensure that there is maternal preference of complementary food if a food is to be widely accepted (Muroki et al., 1997). Involving mothers in nutrition education activities is recommended for improved nutritional status of young infants (Muroki et al., 1997; Abebe et al., 2006), and the mothers in our study were enthusiastic about preparing the Winfood complementary foods. 
Consistency has been found to affect acceptability of complementary porridge (Owino et al., 2007). The Codex Standard (1981) for processed cereal-based foods for infants and children states that reconstituted dry cereal should be suitable for spoon feeding of infants and children. Previous studies have reported that mothers preferred semi-liquid porridges which are easy to spoon feed (Muroki et al., 1997; Mosha \& Svanberg, 1993). If the porridge has a very low or very high consistency, its acceptability may be low. Some previous studies have found that complementary food formulations with addition of sugar were found to be more tasty and appealing than those without sugar, indicating that inclusion of sugar not only increased the energy density of the porridge but enhanced the taste and characteristic improved flavour (Martin et al., 2010; Muhimbula et al., 2011). Owino et al., 2007 found that sweetness improved the acceptability of $\alpha$-amylase-treated maize-beans-groundnuts-bambaranuts complementary blends. This shows that inclusion of sugar or sweetener is important in the acceptability of product by target groups.

There is evidence that olfactory preferences in infants and young infants are learned, not innate and that they develop slowly (Bovell-Benjamin et al., 1999; Pangborn et al., 1988; Schaal, 1988), even though the process may start as early as in the womb (Marlier et al., 1998; Sonssignan et al., 1997). Although infants and toddlers may detect 'unpleasant' smells, they may not judge them as 'unpleasant' until they are about 5 years of age (Mennella \& Bauchamp, 1997). In general, exposure drives preference, except in those cases when negative reactions from peers or parents teach young children that a given olfactory stimulus is unpleasant (Birch, 1992). In this study however, young children as old as 24 months did not dislike any of the foods and this may mean that all the foods were acceptable among the young ones.

Most of the theoretical base for conducting sensory evaluation relates to normal circumstances where food resources are adequate. Infants who lack adequate food may eat foods eagerly due to hunger, which might not represent an accurate assessment of the acceptability of tested products using standard sensory evaluation procedures. In this study evaluation was done both at a central place and at home to avoid bias due to hunger as well influence of changing the feeding environments. In this study we observed that infants tended to eat more of the served porridge at home compared to the health centre. Apart for the fact that at home there is little observer influence, it is also likely that mothers/caretakers added more sugar and other ingredients to the porridge thereby making it more palatable. This observation may also have been as a result of bias from mother/caretaker self-reported data as opposed to the observed measurements at the health facility. Also, low-income caregivers in such situations may be inclined to give higher scores (Ashbrook \& Doyle, 1985). This suggests the need for applicable methods for conducting sensory evaluation in low-income households with illiterate and semi illiterate participants.

Food fortification may have adverse effects on the sensory qualities of foods especially if fortifying with some foods such as fish and insects due to the high rate of rancidity development. Rancidity is influenced by the type of fatty acid composition of the high oil content foods. However, infants may not always detect the rancid smell in the foods or may not view it as unpleasant or did not care. The logical explanation for this is that their olfactory preferences are not yet well developed (Schaal, 1988; Marlier et al., 1998; Sonssignan et al., 1997). In our study, the infants' non-verbal cues were mostly positive, intake was good and it is difficult to imagine how mothers could have influenced such responses. The degree of liking of the porridges was read by the primary caretaker from non-verbal cues exhibited by the toddler during feeding. The indirect approach of using non-verbal cues as indicators of acceptance by infants and young children has been used before by researchers (Mennella \& Bauchamp, 1997; Birch, 1992; Ashbrook \& Doyle, 1985; \& Melcer 1997), and it is the practice of choice in the baby-food industry (Kevin, 1995; Neumann et al., 2002). Many variables (other than sensory variables) affect consumer behaviour. It is speculated, however, that the respective weights of these non-sensory (mostly cognitive or psychological) variables in decisions to consume must be much lower for infants and young children than they are for adults, simply because the former are not aware of most of them (Bovell-Benjamin et al., 1999).

\section{Conclusion}

All three foods were acceptable by the target population with no adverse effects and may be developed further and be used for efficacy trial. Despite the differences, it is important to notice all the food scored reasonably high in the parameters tested.

\section{Acknowledgements}

This work is indebted to the mothers and their young children who willingly participated in the study. The research team is grateful to the research assistants, the Mumias District Health Management Team as well as the Danish International Development Assistance (DANIDA) for financial support through the WINFOOD Project. 
WINFOOD Project is a multi-country collaborative project involving the Department of Human Nutrition, Faculty of Science, University of Copenhagen, Denmark; Institute of Tropical and Infectious Diseases, University of Nairobi, Kenya; Department of Food Science and Technology, Jomo Kenyatta University, Kenya and Department of Fisheries Post-harvest Control, Cambodia. Aagaard Hansen Jens is highly appreciated for his objective critique of the earlier version of this manuscript. None of the authors had a conflict of interest to disclose.

\section{References}

Abebe, Y., Barbara, J. S., Margaret, J. H., \& Gail, E.G. (2006). Nutritive value and sensory acceptability of cornand Kocho-based foods supplemented with legumes for infant Feeding in southern Ethiopia. African Journal of Food, Agriculture, Nutrition and Development, 1(6), 1-19. http://www.ajol.info/index.php/ajfand/article/viewFile/19172/62502

Allen, L. H. (2003). Interventions for Micronutrient Deficiency Control in Developing Countries: Past, Present and Future. Journal of Nutrition, 133(11), 3875S-8S. http://jn.nutrition.org/content/133/11/3875S.full.pdf+html

Ashbrook, S., \& Doyle, M. (1985). Infants acceptance of strong-and mild-flavoured vegetables. Journal of Nutrition Education, 17, 5-6. http://dx.doi.org/10.1016/S0022-3182(85)80009-1

Ayieko, M. A. (2007). Nutrition value of selected species of reproductive Isoptera and Ephemeroptera within the ASAL of Lake Victoria basin. Journal of Discovery and Innovations, 19(2), 126-130.

Birch, L. L. (1992). Children preference for high-fat foods. Nutrition Reviews, 50, 249-255. http://dx.doi.org/10.1111/j.1753-4887.1992.tb01341.x

Bovell-Benjamin, A. C., Lindsay, H. A., \& Jean-Xavier, G. (1999). Toddlers' acceptance of whole maize meal porridge fortified with Ferrous Bisglycinate. Food Quality and Preference, 10, 123-128. http://dx.doi.org/10.1016/S0950-3293(98)00058-5

Codex Alimentarius. (1981). Standard for Processed Cereal-Based Foods for Infants and Children, Codex Stan, 74. FAO, Rome.

Dewey, K. G., \& Brown, K. H. (2003). Update on Technical Issues Concerning Complementary Feeding of Young Children in Developing Countries and Implications for Intervention Programs. Food and Nutrition Bulletin, 24, 5-28. http://www.who.int/nutrition/publications/infantfeeding/FNB_24-1_WHO.pdf

Kevin, K. (1995). You've come a long way, baby-food! Food Process, 56(2), 61-64.

Kinyuru, J. N., Konyole, S. O., Kenji, G. M., Onyango, C. A., Owino, V. O., Owuor, B., ... Ross, N. (2010). Ethnobotany and Prioritization of Traditional Foods for Development of Nutrient-Dense complementary food in Western Kenya. Unpublished progress report. Winfood Project.

Lutter, C. K., \& Rivera, J. A. (2003). Nutritional status of infants and young children and characteristics of their diets. Journal of Nutrition, 133, 2941S-2949S. http://jn.nutrition.org/content/133/9/2941S.full.pdf

Marlier, L., Schaal, B., \& Soussignan, R. (1998). Neonatal responsiveness to the odour of amniotic and lacteal fluids: a test of perinatal chemosensory continuity. Child Development, 69(3), 611-623. http://www.jstor.org/stable/1132193

Martin, H., Laswai, H., \& Kulwa, K. (2010). Nutrient content and acceptability of soybean based complementary food. African Journal of Food, Agriculture Nutrition and Development, 10, 2040-2049. http://www.bioline.org.br/request?nd10008

Meilgaard, M., Civille, G. V., \& Carr, B. T. (2007). Sensory evaluation techniques. $4^{\text {th }}$ Edn. Chapter 12, pp 225-311. CRC Press, Boca Raton, FL.

Melcer, T. (1997). The human infants' ingestive and hedonic responses during spoon feeding following repeated exposure to novel vanilla flavouring in bananas (abstract). International symposium on olfaction and taste $X I I$, San Diego, CA.

Mennella, J. A., \& Bauchamp, G. K. (1997). Mothers' milk enhances the acceptance of cereal during weaning. PediatricResearch, 41, 188-192. http://dx.doi.org/10.1203/00006450-199702000-00006

Mensa-Wilmot, Y., Phillips, R. D., \& Sefa-Dedeh, S. (2001). Acceptability of extrusion cooked cereal/legume weaning food supplements to Ghanaian mothers. International Journal of Food Sciences and Nutrition, 52(1), 83-90. 
Mosha, A. C., \& Svanberg, U. (1993). Preparation of weaning foods with high nutrient density using flour of germinated cereals. Food and Nutrition Bulletin, 5, 10-14.

Muhimbula, H. S., Abdulsudi, I., \& Kinabo J. (2011). Formulation and sensory evaluation of complementary foods from local, cheap and readily available cereals and legumes in Iringa,Tanzania. African Journal of Food Science, 26-31. http://www.academicjournals.org/ajfs/PDF/Pdf2011/Jan/Muhimbula\%20et\%20al.pdf

Muroki, N. M., Maritim, G. K., Karuri, E. G., Tolong, H. K., Imungi, J. K., KogiMakau, W., .. Maretzki, A. N. (1997). Involving rural Kenyan women in the development of nutritionally improved weaning foods:

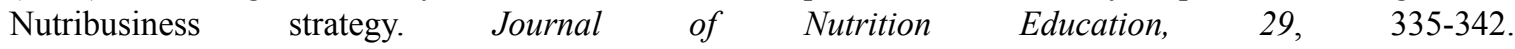
http://dx.doi.org/10.1016/S0022-3182(97)70248-6

Neumann, C., Harris, D. M., \& Rogers, L. M. (2002). Contribution of animal source foods in improving diet quality and function in children in the developing world. Nutrition Research, 22, 193-220. http://dx.doi.org/10.1016/S0271-5317(01)00374-8

Owino, V. O., Sinkala, M., Amadi, B., Tomkins, A., \& Filteau, S. M. (2007). Acceptability, storage stability and costing of $\alpha$-amylase-treated maize-beans-groundnuts-bambaranuts complementary blend. Journal of the Science of Food and Agriculture, 87, 1021-1029. http://dx.doi.org/10.1002/jsfa.2799

Pangborn, R. M., Guinard, J. X., \& Davis, R. G. (1988). Regional aroma preferences. Food Quality and Preference, 1, 11-19. http://dx.doi.org/10.1016/0950-3293(88)90003-1

Parker, M. E., Schroeder, D. G., Begin, F., \& Hurtado, E. (1998). Maternal preferences for consistency of complementary foods in Guatemala. Food and Nutrition Bulletin, 19, 6-12.

Schaal, B. (1988). Olfaction in infants and children: developmental and functional perspectives.ChemicalSenses, 13(2), 145-190. http://dx.doi.org/10.1093/chemse/13.2.145

Soussignan, R., Schaal, B., Marlier, L., \& Jiang, T. (1997). Facial and autonomic responses to biological and artificial olfactory stimuli in human neonates: Re-examining early hedonic discrimination of odours. Physiology and Behaviour, 62(4), 745 - 758. http://dx.doi.org/10.1016/S0031-9384(97)00187-X

SPSS. Statistical data analysis. (2010). Chicago, USA: SPSS Inc.

Valid International. (2006). Community Based Therapeutic Care (CTC). A Field Manual. $1^{\text {st }}$ ed.ValidInternational. Oxford. http://www.concernusa.org/media/pdf/2007/10/CTC_Manual_v1_Oct06.pdf

World Food Programme. (2010).Technical Specifications for the manufacture of: Corn Soya Blend for Young Children and Adults- CSB plus Version 2.1.

World Health Organization. (2008). Indicators for assessing infant and young child feedingpractices.WHO/NUT/2008.1,Geneva,WHO. 